\title{
Un Palique de Clarín \\ y un estudio acerca de un cuento chileno de Demófilo: adendas a dos capítulos de la folclorística española del siglo XIX
}

\author{
José Manuel PedrosA \\ (Universidad de Alcalá)
}

En mi artículo «Demófilo y Menéndez Pidal: folclore, antropología y filología (o tragedia y epopeya)», que fue publicado en el primer número extraordinario (2017) del Boletín de Literatura Oral, no hubo espacio (por tratarse de un volumen de $768 \mathrm{pp}$. impreso en papel) para integrar las reproducciones facsimilares de un «Palique» que Leopoldo Alas, Clarín, publicó en el Madrid Cómico del 25 de julio de 1896 (pp. 257258); y de un artículo que Antonio Machado y Álvarez, Demófilo, publicó en el diario La América los días 8 (p. 15) y 28 (p. 15) de mayo y 28 de junio (pp. 14-15) y 8 de julio (p. 15) de 1883.

Debido a esto, aprovechando las ventajas de los volúmenes publicados exclusivamente en formato electrónico, la redacción de la revista decidió reproducir estas páginas en el presente número del $B L O$, con el fin de que los lectores interesados pudiesen acudir directamente a ellas.

Sin embargo, con posterioridad a esta decisión, el $B L O$ tomó la determinación de asumir en lo sucesivo la licencia de publicación Creative Commons Attribution 4.0 International license, que presenta incompatibilidades con las condiciones legales de reproducción de los fondos de la Biblioteca Nacional de España, de donde proceden los mencionados ensayos.

Nos limitamos, por tanto, a indicar la URL de estos artículos, accesibles desde los siguientes enlaces de la Biblioteca Digital Hispánica:

$<\mathrm{http}$ //hemerotecadigital.bne.es/issue.vm?id=0002100439> (Madrid Cómico del 25 de julio de 1896 (pp. 257-258)

$<$ http://hemerotecadigital.bne.es/issue.vm?id=0002298117\&search=\&lang=es $>$ (La América, 8 de mayo de 1883, p. 15)

$<$ http://hemerotecadigital.bne.es/issue.vm?id=0002298164\&search=\&lang=es $>$ (La América, 28 de mayo de 1883, p. 15)

$<$ http://hemerotecadigital.bne.es/issue.vm?id=0002298337\&search=\&lang=es $>$ (La América, 28 de junio de 1883, p. 14-15)

$<$ http://hemerotecadigital.bne.es/issue.vm?id=0002298405\&search=\&lang=es $>$ (La América, 8 de julio de 1883, p. 15)

$$
9
$$

